injury, and at how all this information is currently being used to guide planning for injury prevention.

Schmertmann and Williamson's article provides an overview of the size and nature of the problem of injuries in NSW. It reports that each year injuries are responsible for approximately 2500 deaths and more than 178,000 hospitalisations. Their analysis of the data highlights the burden of intentional injuries (such as suicide and violence) particularly in males. Table 3 of their article illustrates how the groups that are at higher risk vary when the data are examined by injury mechanism and injury outcome. These findings have implications for the planning of prevention strategies.

The article by Potter-Forbes presents the methodological challenges associated with economic costing of injury at a population level. With NSW estimates of 1.48-1.68 billion dollars in direct health care costs due to injuriesand hospital separations data able to pinpoint the major contributors to this cost-these methodologies can be utilised to inform advocacy for investment in injury prevention.

Good information systems and investment in evaluation are the cornerstones for planning effective injury prevention strategies. In Williamson's article, we see how the NSW Injury Risk Management Research Centre is contributing to our rapidly growing knowledge-base of injury research in NSW. Sefton's article covers the evaluation methods being employed in NSW Safe Community Pilot Projects, where the focus is on risk management at local levels-finding local solutions for local risks.

Two articles examine specific types of injuries or groups at risk: Williamson and Schmertmann explore drowning and near-drowning among children; Heslop describes the results from a study of injuries to Aboriginal people in the Mid-North Coast Area. Through two other brief reports, we are presented with examples of initiatives in planning for injury prevention: the NSW Water Safety Task Force, and the response of the NSW Motor Accidents Authority to the NSW Child Death Review Team 1998-99 Report with regard to the requirements for action to prevent child deaths and injuries in driveways.

Through all the issues in this ongoing Bulletin series on injury in NSW, we are provided with a wealth of information that can inform local, regional, and statewide planning in injury prevention. With injuries affecting all age groups, all socioeconomic groups, and all geographic areas, well-planned interventions are a sound investment for public health.

\title{
A BRIEF OVERVIEW OF INJURY IN NEW SOUTH WALES
}

\section{Marcia Schmertmann and Ann Williamson \\ NSW Injury Risk Management Research Centre \\ University of New South Wales}

Injury is a leading cause of morbidity and mortality in NSW. Each year, an estimated 2500 NSW residents die as the result of an injury, and more than 178,000 are hospitalised. In 1999, injury was the leading cause of death among NSW residents aged 1-44 years, and injury and poisonings were the sixth most common cause of death and the fourth most common cause of hospitalisation. This article provides a brief overview of the patterns and circumstances of injury in NSW, using information presented in the NSW Injury Profile, which is produced annually by the NSW Injury Risk Management Research Centre.

\section{METHODS}

\section{Case definitions}

The case definitions of injury mechanism, injury mortality, and injury morbidity used in the NSW Injury Profile are described below:

\section{Injury mechanism}

Injuries are usually classified in terms of their cause and intent. An injury mechanism (represented by an E-code selected from the International Classification of Disease) is defined as the external object or circumstance that caused the injury, such as a motor vehicle crash. The intent can be accidental, intentional, or undetermined. Intentional injuries are usually grouped together on the basis that they were either self-inflicted or inflicted by another person or persons.

Seven major mechanisms of injury are analysed in the NSW Injury Profile: drowning, falls, fire-burns, interpersonal violence, motor vehicle crashes, poisonings, and suicide. All intentionally self-inflicted injuries were grouped into the suicide injury mechanism and all injuries intentionally inflicted by another were grouped into the interpersonal violence mechanism. Analysis of injuries resulting from complications of medical and/or surgical care (commonly referred to as 'adverse events') is also presented. 


\section{Injury mortality}

Injury mortality is defined as a case where the underlying cause of death was determined to be an external cause of injury (see 'injury mechanism'). In some cases, the injury mechanism identified will be an adverse event and will be linked to a diagnosis code (which is also selected from the International Classification of Disease) that is not injury-related. In these cases, the patient was probably being treated at the hospital for a medical condition (for example, a heart attack) and suffered an adverse event that resulted in death.

\section{Injury morbidity}

Injury morbidity is defined as a case where either an injury code was assigned as the principle diagnosis, or at least one E-code was assigned for an episode of care in a hospital, not resulting in death. For these cases, an injury will be considered the main reason for hospitalisation. In some cases, the identified injury mechanism will be an adverse event and will be linked to a diagnosic code that is not injury-related (for example, a heart attack).

\section{Sources of data \\ Mortality}

Data were obtained for NSW for 1986-1999 from the Australian Bureau of Statistics (ABS) for all E-coded death records. Data from 1986 to 1998 were coded using the World Health Organization (WHO) ICD-9, and data from 1999 was coded using WHO ICD-10.

\section{Morbidity}

All in-patient (hospitalisation) records were obtained from the NSW Department of Health for fiscal years 1991-92 to 1999-00. Data from fiscal years 1991-92 to 1997-98 were coded using ICD-9-CM and data from fiscal years 1998-99 to 1999-00 were coded using ICD-10-AM.

\section{Analyses}

Age and gender-specific death and hospitalisation frequencies and rates were calculated for all major injury mechanism cases from 1995 to 1999 using standard five- year age groups. For each injury mechanism, age-adjusted rates were calculated annually from 1986 to 1999 for deaths, and from 1992 to 1999 for hospitalisations. Ageadjusted death and hospitalisation rates were calculated by applying the direct standardisation method (with fiveyear age groups) and using the 1991 Australian population census as the standard population.

\section{RESULTS}

\section{Injury Mortality in NSW}

Table 1 shows the number of deaths and the death rates by injury mechanism for all people in NSW, and for males and females, from 1995 to 1999.

From Table 1 it can be calculated that 34 per cent of the injury related deaths in NSW for this period were due to suicide and 24 per cent were due to motor vehicle injuries. When combined, these two categories account for more than 50 per cent of all deaths due to injury. Deaths due to drowning (four per cent) and adverse events (one per cent) were much less common. Table 1 also shows that death rates for males were higher than for females for all injury mechanisms and that males account for 70 per cent of all injury deaths between 1995 and 1999. For the same period, suicide and drowning occurred among males almost three times more often than among females.

Figure 1 compares the trend in death rates between 19861999 for four of the injury mechanisms listed in Table 1: falls, motor vehicle crashes, poisoning, and suicide.

In 1991, suicide replaced motor vehicle crashes as the leading cause of injury related death and exhibited a statistically significant increase between 1986 and 1997; however, the suicide death rate also shows a statistically significant decrease from 1997 to 1999. Of the other injury mechanisms shown in Figure 1, poisoning death rates fluctuated between 1986 and 1997, but showed statistically significant increases from 1997 to 1998 and again from 1998 to 1999. Motor vehicle transport death

\section{TABLE 1}

NUMBER OF DEATHS AND DEATH RATES/100,000* BY INJURY MECHANISM, NSW, 1995-1999

\begin{tabular}{|c|c|c|c|c|c|c|}
\hline Injury Mechanism & $\begin{array}{l}\text { Total } \\
\text { Number }\end{array}$ & $\begin{array}{c}\text { Rate } \\
/ 100,000\end{array}$ & $\begin{array}{l}\text { Number of } \\
\text { Males }\end{array}$ & $\begin{array}{c}\text { Male Rate } \\
/ 100,000\end{array}$ & $\begin{array}{l}\text { Number of } \\
\text { Females }\end{array}$ & $\begin{array}{c}\text { Female Rate } \\
1 / 100,000\end{array}$ \\
\hline Suicide & 4,151 & 13.1 & 3,276 & 21.1 & 875 & 5.4 \\
\hline Motor Vehicle & 2,915 & 9.3 & 2,032 & 13.4 & 883 & 5.4 \\
\hline Falls & 901 & 2.5 & 541 & 3.6 & 360 & 1.6 \\
\hline Poisoning & 870 & 2.8 & 649 & 4.2 & 221 & 1.4 \\
\hline Interpersonal Violence & 566 & 1.8 & 401 & 2.6 & 165 & 1.0 \\
\hline Drowning & 465 & 1.5 & 366 & 2.3 & 99 & 0.6 \\
\hline Fire-burns & 223 & 0.7 & 142 & 0.9 & 81 & 0.5 \\
\hline Adverse Events & 121 & 0.3 & 59 & 0.4 & 62 & 0.3 \\
\hline All Injury & 12,341 & 38.1 & 8,671 & 56.8 & 3,670 & 20.2 \\
\hline
\end{tabular}


FIGURE 1

YEARLY TREND IN DEATH RATES BY INJURY MECHANISM, NSW, 1986-1999

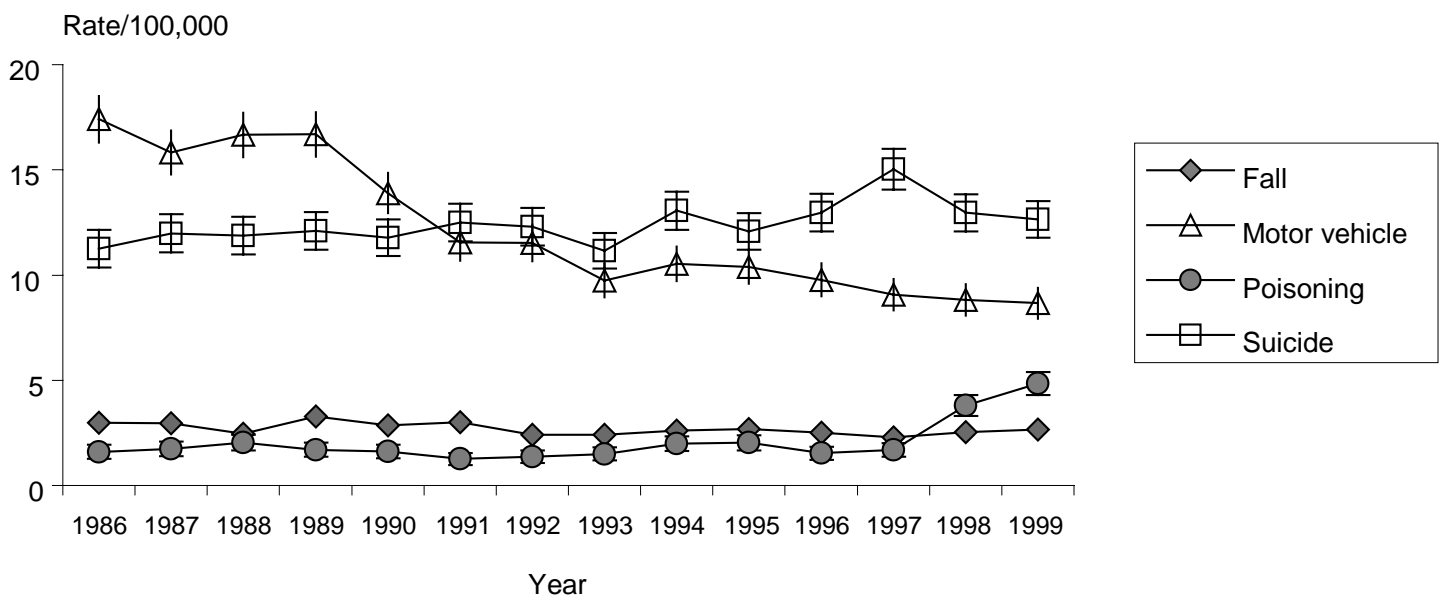

\section{TABLE 2}

NUMBER OF HOSPITALISATIONS AND HOSPITALISATION RATES/100,000* BY INJURY MECHANISM, NSW, 1995-1999

\begin{tabular}{|c|c|c|c|c|c|c|}
\hline Injury Mechanism & $\begin{array}{c}\text { Total } \\
\text { Number }\end{array}$ & $\begin{array}{c}\text { Rate } \\
/ 100,000\end{array}$ & $\begin{array}{c}\text { Number of } \\
\text { Males }\end{array}$ & $\begin{array}{c}\text { Male Rate } \\
/ 100,000\end{array}$ & $\begin{array}{c}\text { Number of } \\
\text { Females }\end{array}$ & $\begin{array}{c}\text { Female Rate } \\
/ 100,000\end{array}$ \\
\hline Adverse Events & 309,102 & 922.1 & 155,853 & 997.8 & 153,240 & 870.9 \\
\hline Fall & 224,141 & 661.7 & 97,939 & 644.8 & 126,202 & 646.2 \\
\hline Motor vehicle & 73,245 & 238.0 & 47,439 & 311.9 & 25,806 & 163.3 \\
\hline Suicide & 36,617 & 119.9 & 15,770 & 102.9 & 20,846 & 137.5 \\
\hline Assault & 32,353 & 107.8 & 24,849 & 165.0 & 7,503 & 49.5 \\
\hline Poisoning & 24,582 & 80.0 & 12,299 & 80.6 & 12,283 & 79.5 \\
\hline Fire-burns & 12,838 & 42.0 & 8,074 & 52.9 & 4,764 & 31.0 \\
\hline Drowning & 1,168 & 3.9 & 792 & 5.2 & 376 & 2.5 \\
\hline All Injury & 963,300 & $2,978.1$ & 535,910 & $3,486.7$ & 427,372 & $2,452.3$ \\
\hline
\end{tabular}

\section{FIGURE 2}

YEARLYTREND IN HOSPITALISATION RATES BY MECHANISM, NSW, 1992-1999

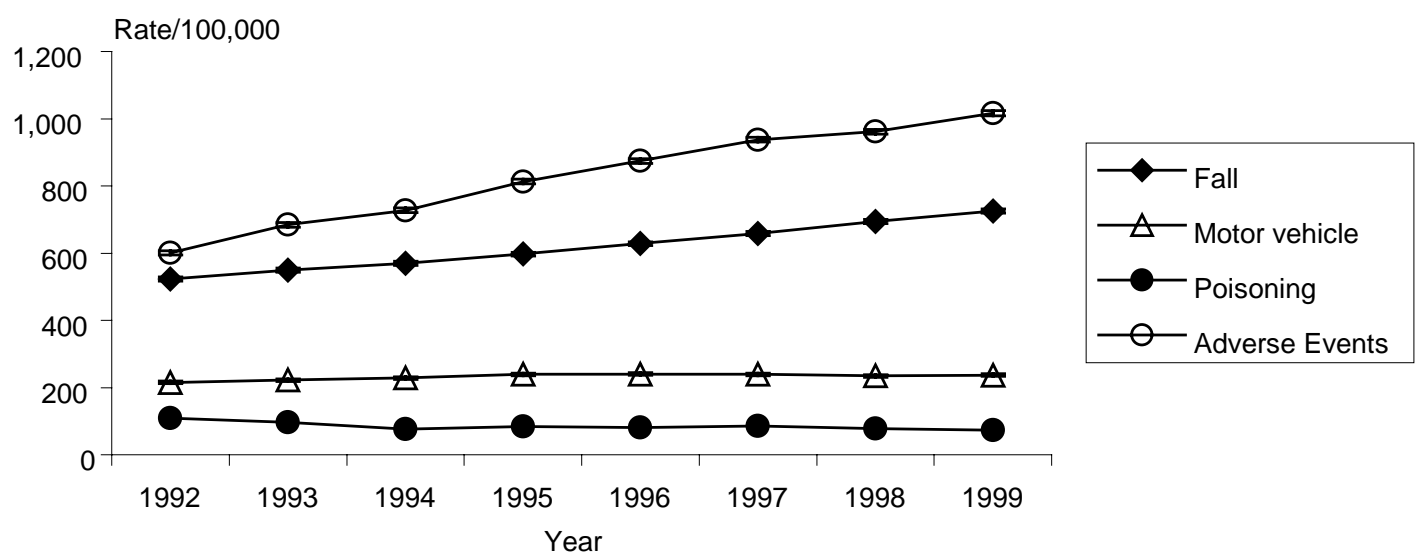


rates showed a statistically significant decrease between 1986 and 1999 and were decreasing the most rapidly.

\section{Injury Morbidity in NSW}

Table 2 shows the number of hospitalisations and the hospitalisation rates by mechanism of injury for all people in NSW, and for males and females separately, from 1995 to 1999.

From Table 2 it can be shown that 32 per cent of the injury related hospitalisations in NSW were due to adverse events and 23 per cent were due to falls. These two categories of injury together account for more than 50 per cent of all injury hospitalisations. Hospitalisations due to fire-burns (1.3 per cent) and near-drowning ( 0.1 per cent) were much less common. Table 2 also shows that hospitalisation rates for males were higher than for females for all mechanisms of injury except for falls and attempted suicide; and that 56 per cent of all injury hospitalisations between 1995 and 1999 were among males. The near-drowning hospitalisation rates from 1995 to 1999, in particular, were much higher for males than females.

Figure 2 compares the trend in hospitalisation rates between 1992 and 1999 for four of the injury mechanisms listed in Table 2: falls, motor vehicle crashes, poisoning, and adverse events.

Figure 2 shows that the hospitalisation rates for adverse events and falls exceeded the rates for other injury types each year since 1992. Adverse events and falls hospitalisation rates showed statistically significant increases between 1992 and 1999. Motor vehicle crashes were the next most common reason for injury-related hospitalisation, but the rates were less than half those shown for adverse events and falls and remained stable from 1992 to 1999.

Table 3 summarises the at risk age and gender groups for injury deaths and hospitalisations by injury mechanism, as well as the injury mechanism subcategory that accounted for the largest proportion of cases.

As Table 3 shows, children under the age of five had the highest rates for drowning deaths and near-drowning hospitalisations, fire-burns and poisoning hospitalisations. Overall, adults aged 15-44 years had higher rates for interpersonal violence deaths and hospitalisations, motor vehicle transport deaths and hospitalisations, poisoning deaths and deaths and hospitalisations due to self-harm, although the specific age group at risk varied with each injury mechanism. Adults 50 years and older had the highest rates for fall related deaths and hospitalisations, as well as adverse event deaths and hospitalisations; although, again, the specific age group at risk varied with each injury mechanism.

\section{DISCUSSION}

Injury is one of the leading causes of morbidity and mortality in NSW, and, unlike other leading causes of morbidity and mortality, injury has a serious effect on both the young and old.

The death and hospitalisation data analyses provide different pictures of the major causes of injury in NSW. When considering injuries that result in death, suicide is

\section{TABLE 3}

SUMMARY TABLE OF AT-RISK GROUPS FOR DEATHS AND HOSPITALISATIONS BY INJURY MECHANISM, NSW, 1995-1999

\begin{tabular}{|c|c|c|c|c|c|c|}
\hline \multirow[t]{2}{*}{ Injury Mechanism } & \multicolumn{3}{|c|}{ Deaths } & \multicolumn{3}{|c|}{ Hospitalisations } \\
\hline & $\begin{array}{l}\text { Age } \\
\text { Group }\end{array}$ & Gender & $\begin{array}{c}\text { Injury } \\
\text { Mechanism } \\
\text { Subcategory }\end{array}$ & $\begin{array}{l}\text { Age } \\
\text { Group }\end{array}$ & Gender & $\begin{array}{c}\text { Injury } \\
\text { Mechanism } \\
\text { Subcategory }\end{array}$ \\
\hline Suicide & 20-39 & Males & Suffocation & 20-39 & Females & Poisoning \\
\hline Motor Vehicle & $15-24,75+$ & Males & Drivers & $15-24$ & Males & Drivers \\
\hline Falls & $70+$ & Males & $\begin{array}{l}\text { One level } \\
\text { to another }\end{array}$ & $70+$ & Females & On same level \\
\hline Poisoning & $25-44$ & Males & $\begin{array}{l}\text { Narcotics and } \\
\text { hallucinogens }\end{array}$ & Under 5 & Female & $\begin{array}{l}\text { Other and } \\
\text { unspecified }\end{array}$ \\
\hline $\begin{array}{l}\text { Interpersonal } \\
\text { Violence }\end{array}$ & $25-29$ & Males & $\begin{array}{l}\text { Sharp or blunt } \\
\text { objects }\end{array}$ & $20-24$ & Males & $\begin{array}{l}\text { Struck by or against } \\
\text { another person or } \\
\text { object }\end{array}$ \\
\hline Drowning & Under 5 & Males & Natural body of water & Under 5 & Males & Natural body of water \\
\hline Fire-burns & $70+$ & Males & Fires in buildings & Under 5 & Males & $\begin{array}{l}\text { Burns from } \\
\text { substances or } \\
\text { objects }\end{array}$ \\
\hline Adverse Events & $65+$ & $\begin{array}{l}\text { Males, } \\
\text { Females }\end{array}$ & $\begin{array}{l}\text { Abnormal reaction } \\
\text { or a complication } \\
\text { without a mention } \\
\text { of a misadventure } \\
\text { at time of procedure }\end{array}$ & $50+$ & $\begin{array}{l}\text { Males, } \\
\text { Females }\end{array}$ & $\begin{array}{l}\text { Abnormal reaction } \\
\text { or a complication } \\
\text { without a mention } \\
\text { of a misadventure } \\
\text { at time of procedure }\end{array}$ \\
\hline
\end{tabular}


the leading cause followed by motor vehicle-related injury. If the focus of the analysis is on injuries that result in hospitalisation, then adverse events and fall-related injury are the most frequent cause.

The analyses in the NSW Injury Profile also provide different pictures of the at-risk age and gender groups. The at-risk age and gender groups are similar for injury deaths and hospitalisations when looking at all injury mechanisms combined, but change when an injury mechanism is analysed separately, as illustrated by Table 3 .

The NSW Injury Profile depicts only the 'tip of the iceberg' regarding the effects that injury has on the people of NSW. Beyond the data presented in this article are the scores of injuries seen and treated every day by general practitioners, which are not recorded by existing systems of data collection. In the case of injuries that are captured in current systems of data collection (that is, deaths, hospitalisations, emergency department visits to some hospitals, and ambulance service calls), information describing the events that lead to the injury is often unavailable. This has resulted in large gaps in the data that are required to inform steps to prevent certain types of injury. Substantial gains in the field of injury prevention rest with rectifying these gaps in the available data.

\section{CONCLUSION}

This profile of injury in NSW has provided insight into the patterns of injury. The information will be used by the NSW Injury Risk Management Research Centre to further examine different mechanisms of injury, to develop targeted research plans to address areas of concern, and to identify approaches to injury prevention activities.

A copy of the NSW Injury Profile is available at www.irmrc.unsw.edu.au.

\section{NSW INJURY RISK MANAGEMENT RESEARCH CENTRE}

\section{Ann Williamson}

NSW Injury Risk Management Research Centre

University of New South Wales

The Injury Prevention and Policy Unit of the NSW Department of Health has developed a partnership with the NSW Roads and Traffic Authority, the Motor Accidents Authority, and the University of New South Wales, to establish the NSW Injury Risk Management Research Centre (IRMRC) at the University of New South Wales. This article briefly describes the aim, initiatives, activities, and research projects of the IRMRC.

\section{AIM OF THE IRMRC}

The aim of the IRMRC is to undertake and facilitate research on the prevention of all types of injury, and to develop effective solutions for problems associated with injury. The Centre provides industry and other agencies with a single point of access to expertise in a wide range of disciplines in the field of injury risk management.

\section{INITIATIVES OF THE IRMRC}

The IRMRC has three major initiatives:

- to identify and negotiate access rights to all relevant injury databases in order to conduct data mining and data analysis activities that will assist in the identification and subsequent monitoring of injury issues;

- to develop a database on injury in NSW. This is fundamental to determining the direction of the IRMRC's research activities and would also provide valuable advice to stakeholders and the public;

- to conduct research and to work in partnership with other researchers to encourage investigation of areas most likely to reduce the frequency and/or severity of injury.

\section{ACTIVITIES OF THE IRMRC}

The core activities of the IRMRC are to:

- establish a comprehensive information system;

- collate injury data across agencies;

- analyse data and provide advice for prevention;

- provide a clearing house for expertise;

- review and analyse literature in the field;

- research causes and control of injury;

- assist organisations to improve injury data collections.

\section{RESEARCH AREAS OFTHE IRMRC}

Some examples of the research areas associated with the identification, analysis and management of injury risks being coordinated by the IRMRC are: 